gravity of the system is $a_{1}=2^{\prime \prime} .33$. Computing the co-efficients of $\frac{1}{\pi}$ for the thirteen years for which $\mathrm{I}$ have spectroscopic results, the following observation equations are obtained:-
No.
DATE. 1868.1

\subsection{1}

1877.16

1878.16

1880.18

1881.14

1882.21

1883.17

1884.11

1885.09

1886.00

1887.05

1887.82
Giving the weight unity to each of these, the following normal equations result:-

$$
\begin{aligned}
13 V_{0}-5.2 \frac{1}{\pi} & =+100 \\
-5.2 V_{0}+2.124 \frac{1}{\pi} & =-39.86 \\
34 . &
\end{aligned}
$$

Hence $\pi=0^{\prime \prime} .34$.

The only direct determinations of the parallax of Sirius that $I$ have at hand are those of Henderson and Peters $\left(0^{\prime \prime} .150\right)$, Gyldén $\left(0^{\prime \prime} .193\right)$, and Gill and Elkin $\left(0^{\prime \prime} .39\right)$. The agreement between this last result and the one deduced above by the spectroscopic method is of course purely accidental, the Greenwich measures being too rough to furnish us with a result even passably good. It is to be hoped that measures may be made, with improved apparatus, that will enable us, in the course of time, to apply the spectroscopic method to a large number of double stars. Dr. Vogel's photographic measures, taken at Potsdam, are far superior to any thing else the writer has seen in this line, unless the Harvard College measures are $\epsilon x c e p t e d$. They have a very small probable error, and the measures on Venus seem to indicate that bis work is not materially affected by constant errors. As a matter of fact, constant errors are of no importance in deducing parallax by the spectroscope, since they affect $V_{o}$ only, and not $\pi$.

It is plain that the method set forth in this article is open to many objections. It is beset with difficulties, but it should not be discarded or lost sight of for that reason. The fact is, that we must either forever give up the effort to determine the distances to the more remote stars, or we must seek them by this method. Very few stars are near enough for us to measure their parallaxes directly; but the spectroscopic method is still applicable when there is no indication of parallax to the micrometer. The velocity of motion in the line of sight may be measured with equal ease, whether the star is near or remote; and the only limit to the power of the method lies in the increasing closeness of the double star as the distance grows greater, and the corresponding difficulty of determining the orbits. By photographing binary systems at intervals of a few years, and measuring distances and position angles on the negative, much better orbits might be computed than we have at present.

While at work on the numerical example in this article, I have endeavored to find out whether others have not worked at this same problem. My attention has been called to several papers that apparently relate to it, though I have been unable to gain access to more than two of them, and then only for a moment, so that I could give them only a hasty examination. The first paper that I find reference to was by C. Dufour, the title being "Utilisation de l'analyse spectrale pour déterminer la distance de certaines étoiles doubles" (Lausanne, Bulletin des séances de la Société vaudoise des sciences naturelles, vol. xiii., 1874, p. 452). The second paper, by Edward C. Pickering, is entitled "Dimensions of the Fixed Stars, with Especial Reference to Binaries and Variables of the Algol Type," and is in the "Proceedings of the American Academy of Arts and Sciences," 1880, vol. xvi. This paper, as its title indicates, relates more particularly to the dimensions of stellar systems than to their parallaxes. The third paper was read before the Royal Irish Academy on May 24, 1886, by Arthur A. Rambaut, the title being " On the Possibility of determining the Distance of a Double Star by Measures of the Relative Velocities of the Components in the Line of Sight." The method here proposed is not applicable unless both components are bright enough to be observed spectroscopically. It appears to be identical with what I have called the "first method." Finally, Herr J. Palisa published an article on the subject while the present one was in preparation, entitled "Ueber die Bestimmung der Parallaxe von Doppelsternen" (Astr. Nach., No. 2,941, Dec. 12, 1889). I have not seen this paper, but I understand that in it he refers to a dissertation by one Hans Homann, the title of which is " Beitrage zur Untersuchung der Sternbewegung," which presumably touches upon the same subject. A. D. RISTEEN.

Hartford, Conn., June 13.

\section{Temperature in Storms.}

In the "Smithsonian Report for 1865," beginning at p. 340, there is a detailed account of a balloon ascension at Paris on July 27, 1850, during a severe storm of rain with some strong wind gusts. The most interesting point is the severity of the cold encountered, the temperature falling to $-39^{\circ} \mathrm{C}$. at an elevation of seven thousand metres. It is stated that at the beginning of the ascent "a deluge of rain was falling," which shows that it must have been made near the centre of precipitation, if not at the exact stormcentre. It would seem that these observations are confirmatory of those noted by Dr. Hann, to which reference is made by Professor Davis in Science for May $30 . \quad$ M. A. VEEDER. Lyons, N.Y., June 9.

\section{BOOK-REVIEWS.}

The Criminal. By Havelock Ellis. London, Walter Scott; New York, Scribner \& Welford. $12^{\circ}$. \$1.25.

Mr. ELLIS, the editor of this promising series of scientific monographs, has contributed to it in this volume a well-planned and ably executed résumé of modern criminology. So little of this science has hitherto been accessible in English, that this compilation is especially timely. It is an outcome of a pedantic and unscientific view of crime, that we are obliged to speak and accustomed to think of all persons liable to punishment as criminals. There are certain very well marked distinctions between classes of criminals, that should be generally recognized. There is the criminal by passion, the insane criminal, the occasional criminal, the instinctive criminal, the habitual criminal, the professional criminal. While the existence of some of these is rather the crime of the society that breeds them, others are distinctly diseased forms of humanity, which we must study in order to understand and to treat. It is the biological, sociological, and psychological study of the criminal classes, so vigorously pursued in Italy and other countries of Europe, that is described in the present volume. On the physical side, the shape of the cranium, the tendency to asymmetry, the peculiarities of face, the details of the ear, nose, and so on, anomalies of the hair and pigmentation, hereditary characteristics, motor inertia and sensory insensibility, fondness for tattooing, and the like,-these characteristics have been made the subjects of special monographs, and in many cases class distinctions between the criminal and his more normal fellow-being have been successfully laid down. While it is not yet possible to describe accurately and briefly the results of these methods of study, and still less so to apply them to individual cases, enough has been done to indicate that all kinds of abnormalities are more common among criminals than among normal people, and to give interesting glimpses into the nature of these differences. These physical differences are connected with and lead up to moral and intellectual differences, and the studies of the two have advanced together. The moral obtuseness, the lack of sympathy, the selfish and thoughtless satisfaction of sudden and strong impulses, the keen cleverness in certain limited directions but general stupidity in every thing else, the emotional 